CARDIOVASCULAR MEDICINE

\title{
Pre-discharge stress echocardiography and exercise ECG for risk stratification after uncomplicated acute myocardial infarction: results of the COSTAMI-II (cost of strategies after myocardial infarction) trial
}

\author{
A Desideri, P M Fioretti, L Cortigiani, G Trocino, C Astarita, D Gregori, J Bax, J Velasco, L Celegon, \\ R Bigi, S Pirelli, E Picano
}

Heart 2005;91:146-151. doi: 10.1136/hrt.2003.026849

See end of article for authors' affiliations

Correspondence to: Dr Alessandro Desideri Cardiovascular Research Foundation, S Giacomo Hospital, 31033 Castelfranco Veneto, Italy; aldesi@tin.it

Accepted 5 March 2004

\begin{abstract}
Objective: To compare in a prospective, randomised, multicentre trial the relative merits of pre-discharge exercise ECG and early pharmacological stress echocardiography concerning risk stratification and costs of treating patients with uncomplicated acute myocardial infarction.

Design: 262 patients from six participating centres with a recent uncomplicated myocardial infarction were randomly assigned to early (day 3-5) pharmacological stress echocardiography $(\mathrm{n}=132$ ) or conventional pre-discharge (day 7-9) maximum symptom limited exercise ECG ( $n=130$ ).

Results: No complication occurred during either stress echocardiography or exercise ECG. At one year follow up there were 26 events (1 death, 5 non-fatal reinfarctions, 20 patients with unstable angina requiring hospitalisation) in patients randomly assigned to early stress echocardiography and 18 events (2 reinfarctions, 16 unstable angina requiring hospitalisation) in the group randomly assigned to exercise ECG (not significant). The negative predictive value was $92 \%$ for stress echocardiography and $88 \%$ for exercise ECG (not significant). Total costs of the two strategies were similar (not significant).

Conclusion: Early pharmacological stress echocardiography and conventional pre-discharge symptom limited exercise ECG have similar clinical outcome and costs after uncomplicated infarction. Early pharmacological stress echocardiography should be considered a valid alternative even for patients with interpretable baseline ECG who can exercise.
\end{abstract}

$\mathrm{T}$ raditionally, patients after uncomplicated acute myocardial infarction (AMI) have been referred for non-invasive testing to identify those at higher risk for future events on the basis of a positive finding obtained during the examination. Present data show that many physicians refer these patients for direct coronary angiography and subsequent revascularisation. ${ }^{1}$ The rationale of this strategy is the observation that within this low mortality group ( $1-2 \%$ death rate at one year), there are some higher risk patients who may theoretically benefit from aggressive treatment. Nevertheless, the majority of these patients in the thrombolytic era have a (near) normal left ventricular ejection fraction and therefore the most important pathophysiological parameter for prognostic assessment is residual ischaemia. Current guidelines suggest that a patient with uncomplicated AMI should be submitted to exercise ECG either submaximally before or at the maximum level early after hospital discharge, whereas pharmacological stress imaging should be used for patients with an inability to exercise or an uninterpretable baseline ECG. Recent evidence supports the role of pharmacological stress imaging in defining prognosis after an uncomplicated AMI. ${ }^{2-5}$ Nevertheless, prospective randomised trials comparing traditional pre-discharge exercise ECG head to head with early stress echocardiography are lacking. Moreover, in the present era of cost containment, it seems particularly important to compare the relative costs of the two tests.

The COSTAMI-II (cost of strategies after myocardial infarction) trial is a prospective, multicentre, randomised trial that aimed at comparing the cost effectiveness of pre-discharge exercise ECG with pre-discharge pharmacological stress echocardiography after uncomplicated AMI.

\section{METHODS}

\section{Patients}

Between January 1998 and August 2000 we enrolled 262 patients from six European hospitals (four in Italy, one in Spain, and one in Poland). The trial protocol was approved by the local ethics committees of the participating centres.

Patients were eligible when they presented with an uncomplicated AMI admitted within 24 hours of the onset of symptoms. AMI was confirmed by a rise of cardiac enzymes (creatine kinase and creatine kinase MB isoenzyme) of at least twice the upper limit of the reference range within 12 hours of admission. An uncomplicated AMI was defined as follows: (1) no recurrent ischaemic chest pain (with documented ECG changes) lasting five minutes or longer and occurring at least 24 hours after hospital admission; (2) no clinical or radiographic evidence of heart failure; (3) no major arrhythmias; and (4) echocardiographic left ventricular ejection fraction at rest $>40 \%$ on day 3 . Exclusion criteria were age $>75$ years, serious arrhythmias (ventricular fibrillation, sustained ventricular tachycardia, or fixed second or third degree atrioventricular blocks), left bundle branch

Abbreviations: $A M I$, acute myocardial infarction; $C A B G$, coronary artery bypass graft; COSTAMI-II, cost of strategies after myocardial infarction; DANAMI, Danish trial in acute myocardial infarction; EDIC, Echo Dobutamine International Cooperative; EPIC, Echo Persantine International Cooperative; PTCA, percutaneous transluminal coronary angioplasty 
Table 1 Clinical and ECG characteristics of the two patient groups

\begin{tabular}{|c|c|c|c|}
\hline & $\begin{array}{l}\text { Overall } \\
\text { (n=262) }\end{array}$ & $\begin{array}{l}\text { Stress echo } \\
(n=132)\end{array}$ & $\begin{array}{l}\text { Exercise ECG } \\
(n=130)\end{array}$ \\
\hline \multicolumn{4}{|l|}{ Clinical characteristics } \\
\hline Age (years) & $59(10)$ & $58(10)$ & $59(11)$ \\
\hline Female sex & $35(13 \%)$ & $16(12 \%)$ & $19(15 \%)$ \\
\hline Diabetes & $44(17 \%)$ & $23(17 \%)$ & $21(16 \%)$ \\
\hline Smoking & $165(63 \%)$ & $85(65 \%)$ & $79(61 \%)$ \\
\hline Hypertension & $111(42 \%)$ & $57(43 \%)$ & $54(41 \%)$ \\
\hline Previous angina & $56(21 \%)$ & $27(20 \%)$ & $29(22 \%)$ \\
\hline Previous MI & $22(8 \%)$ & $8(6 \%)$ & $14(11 \%)$ \\
\hline Previous revascularisation & $12(5 \%)$ & $5(4 \%)$ & $7(5 \%)$ \\
\hline \multicolumn{4}{|l|}{ Acute Ml characteristics } \\
\hline Non- $Q$ wave on day 3 & $93(35 \%)$ & $44(33 \%)$ & $49(38 \%)$ \\
\hline Thrombolysis & $130(50 \%)$ & $76(58 \%)$ & $54(41 \%)$ \\
\hline Anterior/lateral & $84(32 \%)$ & $42(32 \%)$ & $42(32 \%)$ \\
\hline Inferior/posterior & $131(50 \%)$ & $63(48 \%)$ & $68(53 \%)$ \\
\hline WMSI & $1.44(0.22)$ & $1.38(0.22)$ & $1.50(0.21)$ \\
\hline EF on day $3(\%)$ & $55(7)$ & $55(6)$ & $55(7)$ \\
\hline
\end{tabular}

block, pericarditis, insufficient acoustic window, and poor short term prognosis because of concomitant disease.

\section{Study design}

The study patients gave informed, written consent and were randomly assigned to a study group within 72 hours after the onset of symptoms according to the adaptive allocative procedure. The procedure maximised the probability of balance between the treatment groups within the medical centres and with respect to each of the following variables used for stratification: age, previous MI, use of thrombolysis, ST segment depression on the ECG obtained at entry, and anterior location of the infarct. The allocation sequence was generated by the statistics team in the central laboratory (IRCAB Foundation, Udine, Italy). The random allocation sequence was concealed in numbered envelopes until interventions were assigned.

Patients were enrolled and randomly assigned to early stress echocardiography or pre-discharge exercise ECG by the local investigators. Early stress echocardiography strategy consisted of early (days 3-5) use of pharmacological stress echocardiography and discharge on days 7-9 in case of a negative test result. Pre-discharge exercise ECG consisted of a maximum, symptom limited test on days 7-9 followed by discharge in case of a negative test result. The suggested strategy in case of a positive test (either stress echocardiography or exercise ECG) was coronary angiography followed by ischaemia guided revascularisation.

\section{Pharmacological stress echocardiography}

The stress echocardiography of first choice was dipyridamole stress; dobutamine stress was performed when dipyridamole was contraindicated. Patients were instructed to avoid products containing coffee, tea, or caffeine within eight hours of the tests. For the dipyridamole test, a two dimensional echocardiogram was recorded without withdrawing the medical treatment at rest and in combination with dipyridamole infusion $(0.84 \mathrm{mg} / \mathrm{kg}$ over 10 minutes $)$. The test was interrupted by aminophylline (up to $240 \mathrm{mg}$ ) at the 15th minute in the case of a negative result or when a clear wall motion abnormality appeared. ${ }^{2}$ For the dobutamine test, dobutamine was infused in three minute dose increments, starting from $5 \mu \mathrm{g} / \mathrm{kg} / \mathrm{min}$ up to $40 \mu \mathrm{g} / \mathrm{kg} / \mathrm{min}$. Infusion was stopped as soon as the criteria for positivity were reached during the test. Metoprolol (up to $5 \mathrm{mg}$ ) was given intravenously to reverse the effects of dobutamine.

\section{Diagnostic end points}

Positivity of the test was based on the detection of a transient wall motion abnormality that was absent at baseline or worsened during the test. ${ }^{2}$

Diagnostic end points, apart from development of wall motion abnormalities, were peak drug dose and achievement of conventional non-echocardiographic ischaemic end points ( severe chest pain or ST segment shift $>2 \mathrm{mV}$ ). The test was also stopped, in the absence of diagnostic end points, for one of the following reasons: intolerable symptoms; or limiting asymptomatic side effects consisting of hypertension (systolic blood pressure $>220 \mathrm{~mm} \mathrm{Hg}$ and diastolic blood pressure $>120 \mathrm{~mm} \mathrm{Hg}$ ), hypotension (30 mm Hg decrease in blood pressure), and severe (supra)ventricular arrhythmias.

\section{Echocardiographic analysis}

Patients were monitored by two dimensional echocardiography throughout and up to five minutes after termination of drug infusion. The left ventricular myocardium was divided into 16 segments, and segmental wall motion was graded according to the recommendations of the American Society of Echocardiography ${ }^{6}$ as follows: 1, normal; 2, hypokinetic; 3, akinetic; and 4, dyskinetic. A wall motion score index (obtained by dividing the sum of the individual segmental scores by the number of visualised segments) was calculated at baseline and at peak drug infusion. A test result was considered positive for ischaemia when the wall motion score increased by one or more points in two or more adjacent segments relative to the resting echocardiogram. Akinesia becoming dyskinesia was not considered a sign of ischaemia. ${ }^{7}$ The ejection fraction was calculated on a single plane

Table 2 Test results for both groups

\begin{tabular}{ll}
\hline Test & Result \\
\hline Stress echocardiography & $n=132$ \\
Positive for ischaemia & $48(36 \%)$ \\
Negative for ischaemia & $84(64 \%)$ \\
WMSI rest & $1.38(0.23)$ \\
WMSI peak & $1.50(0.26)$ \\
Exercise ECG & $n=130$ \\
No test & $4(3 \%)$ \\
Positive for ischaemia & $53(41 \%)$ \\
Negative for ischaemia & $73(56 \%)$ \\
Maximum workload (W) & $102(32)$ \\
Peak double product & $18411(5064)$ \\
\hline Results are number (\%) or mean (SD). &
\end{tabular}


Table 3 Subgroup analysis: clinical outcome at one year's follow up

\begin{tabular}{|c|c|c|c|c|c|}
\hline & \multicolumn{2}{|c|}{ Stress echocardiography $(n=132$ ) } & \multicolumn{2}{|c|}{ Exercise ECG $(n=130)$} & \multirow{2}{*}{$\begin{array}{l}\text { No test } \\
(n=4)\end{array}$} \\
\hline & Negative $(n=84)$ & Positive ( $n=48$ ) & Negative $(n=73)$ & Positive $(n=53$ ) & \\
\hline Death & 0 & $1(2.1 \%)$ & 0 & 0 & 0 \\
\hline Reinfarction & $4(4.8 \%)$ & $1(2.1 \%)$ & $2(2.7 \%)$ & 0 & 0 \\
\hline Unstable angina & $5(6 \%)$ & $15(31.3 \%)$ & $7(9.6 \%)$ & $9(17 \%)$ & $1(25 \%)$ \\
\hline
\end{tabular}

according to the area-length method. The enrolling centres passed a quality control analysis according to criteria previously used in the EPIC (Echo Persantine International Cooperative) ${ }^{2}$ and EDIC (Echo Dobutamine International Cooperative $)^{3}$ multicentre studies to guarantee a homogeneous interpretation of stress echocardiography.

\section{Exercise ECG}

A maximum symptom limited exercise ECG was recorded for each patient during medical treatment before discharge. The initial work load of $25 \mathrm{~W}$ was incremented by $25 \mathrm{~W}$ every two minutes. Criteria for stopping the test were severe ischaemia (ST segment depression $>3 \mathrm{~mm}$ or elevation $>1 \mathrm{~mm}$ in leads without Q waves), fatigue, three or more consecutive ventricular extrasystoles, hypertensive response (systolic blood pressure $>240 \mathrm{~mm} \mathrm{Hg}$, diastolic blood pressure $>120 \mathrm{~mm} \mathrm{Hg}$ ), hypotensive response (> $20 \mathrm{~mm} \mathrm{Hg}$ decrease in systolic blood pressure), and worsening angina. ST segment depression $>1 \mathrm{~mm}$ defined a positive exercise ECG. ST segments were analysed on site by the local investigators.

\section{Follow up and cardiac events}

The primary end point was cost effectiveness of the diagnostic strategies. The secondary end point was quality of life evaluation. Patients were seen at one and six months and one year after discharge. Cardiac events, use of resources, costing, and quality of life were recorded.

Cardiac events were death, non-fatal reinfarction, and admission for unstable angina. Unstable angina was defined as an episode of chest pain-prolonged at rest, of new onset, or accelerating symptoms of stable angina-and exclusion of myocardial infarction by ECG or enzymes. In case of multiple events, only the first occurrence for each type was considered. For the combined end point only the first occurrence of any of the end points was counted. Local investigators, unblinded to group assignment, assessed cardiac events on the basis of hospital charts.

\section{Use of resources and cost of care}

Use of resources was calculated considering direct medical costs of hospitalisations, investigations, and interventions. Hospitalisations were recorded in terms of number of days for acute hospitalisations and re-hospitalisations for any reason. Hospitalisations were divided in categories of care distinguishing coronary care unit, non-intensive cardiological or general ward, and other wards. Investigations recorded were exercise ECG, echocardiogram, and coronary angiography. Interventions recorded were percutaneous transluminal coronary angioplasty (PTCA) and coronary artery bypass graft $(\mathrm{CABG})$. For the present analysis direct medical costs were calculated related to initial hospital stay and to follow up at one month, six months, and one year. Costs are expressed in Euros (€). Cost of hospitalisation was estimated from the mean reimbursement for the diagnosis related group in the Friuli Venezia Giulia Region, the site of the coordinating centre. A hospital cost of $€ 407$ was assigned for each day of hospitalisation, with the exception of the first day, for which a cost of $€ 460$ was computed. Similarly, costs of investigations and interventions were calculated taking the same reference, at the following values: coronary angiography $€ 1694$, PTCA $€ 6044$, and CABG $€ 18$ 763. Total medical costs for each patient were measured as the sum of initial hospital costs and follow up hospital and outpatient costs through the end of protocol at one year's follow up. The cost of pharmacological treatment was not included in the total costs.

\section{Quality of life}

Quality of life was assessed by administering the MacNew heart disease health related quality of life test, ${ }^{8}$ a 27 item questionnaire which measures, on a Likert-type response scale (where $1=$ all of the time, to $7=$ none of the time), a generic score, and three specific domains of patients' quality of life. The first one, physical dimension, analyses the limitations in exercising or breathing perceived by patients; the second, social dimension, deals with difficulties in participating in normal social activities; and the third, emotional dimension, identifies the level of self confidence and self esteem.

Each patient received a copy of the questionnaire 2-4 weeks after AMI and at the follow up visits (at six and 12 months).

\section{Statistical analysis}

Power calculation for the study showed that 110 patients in each group were needed at a power of 0.9 and $\alpha=0.05$ to detect a reduction in costs of $€ 250$ with a standard deviation assumed to be equal in the two groups up to $€ 650$. Because this was a low risk population, it was expected that the risk of death and reinfarction at the one year follow up would be quite low, so that an unrealistically large sample size would be needed to detect any difference in terms of clinical events.

Data are reported as median values (with corresponding 25th and 75th centiles) for continuous variables and as percentages (with absolute numbers indicated) for categorical variables. Formal tests aimed at evaluating the difference between strategies modelled each outcome (costs and event rates) separately, always adjusting for individual baseline known confounders (sex, previous AMI, diabetes, anterior or lateral AMI on the admission ECG, left ventricular ejection fraction $<50 \%$, age $>70$ years, and centre effect). ${ }^{9}$ In detail, the following models were constructed:

Table 4 Prognostic value of exercise ECG and stress echocardiography

\begin{tabular}{llllll}
\hline & \multicolumn{2}{l}{ Exercise ECG } & & \multicolumn{2}{l}{ Stress echocardiography } \\
\cline { 2 - 3 } \cline { 5 - 6 } & All events & $95 \% \mathrm{Cl}$ & & All events & $95 \% \mathrm{Cl}$ \\
\hline Sensitivity & $50 \%$ & 0.41 to 0.59 & & $\mathbf{6 7 \%}$ & 0.50 to 0.75 \\
Specificity & $60 \%$ & 0.52 to 0.68 & & $73 \%$ & 0.65 to 0.81 \\
PPV & $17 \%$ & 0.11 to 0.23 & & $31 \%$ & 0.23 to 0.39 \\
NPV & $88 \%$ & 0.82 to 0.94 & & $92 \%$ & 0.87 to 0.97 \\
\hline
\end{tabular}

$\mathrm{Cl}$, confidence interval; NPV, negative predictive value; PPV, positive predictive value. 
Table 5 Use of resources and total costs during follow up

\begin{tabular}{|c|c|c|c|}
\hline & Overall $(n=262)$ & $\begin{array}{l}\text { Stress echocardiography } \\
(n=132)\end{array}$ & Exercise ECG $(n=130)$ \\
\hline PTCA & $57(21.8 \%)$ & $29(22 \%)$ & $28(21.5 \%)$ \\
\hline CABG & $33(12.6 \%)$ & $17(12.9 \%)$ & $16(12.3 \%)$ \\
\hline $\begin{array}{l}\text { Coronary angiography } \\
\text { Hospitalisation (days) }\end{array}$ & $129(49.2 \%)$ & $66(50 \%)$ & $63(49.2 \%)$ \\
\hline 1 & $73(27.9 \%)$ & $38(28.8 \%)$ & $35(26.9 \%)$ \\
\hline$\geqslant 2$ & $37(14.1 \%)$ & $19(14.4 \%)$ & $18(13.9 \%)$ \\
\hline $\begin{array}{l}\text { Duration of hospitalisation } \\
\text { (days) }\end{array}$ & 10 (8 to 14$)$ & $9(8$ to 14$)$ & 10 (8 to 14$)$ \\
\hline Costs $(€)$ & 5225 (3062 to 11939 ) & $5195(2800$ to 11825$)$ & 5431 (3150 to 12289 ) \\
\hline
\end{tabular}

- Costs were modelled as a linear mixed random effect, with centre modelled as a random normal variable, allowing the variance function to be a power function of the fitted expectation $^{10}$

- Times to event were modelled and adjusted by centre by using a marginal estimating equation model in the Cox proportional hazard class ${ }^{11}$

- Re-hospitalisations and revascularisations were modelled by a generalised estimating equation approach, with adjustment for centre effect through an exchangeable correlation structure. ${ }^{12}$

Significance was set at $\mathrm{p}<0.05$. Descriptive and exploratory analysis were calculated by SPSS 7.0 (SPSS Inc, Chicago, Illinois, USA) and statistical models were estimated with S-PLUS 2000 (Insightful Corp, Seattle, Washington, USA).

\section{RESULTS}

\section{Study population}

A total of $132(50 \%)$ patients were randomly assigned to early stress echocardiography and $130(50 \%)$ to pre-discharge exercise ECG. Table 1 shows clinical and AMI characteristics of the study population. Overall, $86.6 \%$ of the patients were men (mean age was 59 (10) years). Mean echocardiographic left ventricular ejection fraction on day 3 was 55 (7)\%. There was no intergroup difference (not significant) in clinical and AMI characteristics of the index infarctions.

\section{Test results}

All 132 patients in the stress echocardiography group completed the test. Of them, 131 underwent dipyridamole stress and one patient dobutamine stress; 99 (75\%) patients were taking a $\beta$ blocker at the time of the test. The test was positive for ischaemia in $48(36 \%)$ patients.
In the exercise ECG group, $126(97 \%)$ of the 130 patients completed the test. Four patients did not do the test because of an inability to exercise $(n=2)$, early post-infarction angina $(n=1)$, or suspicion of left ventricular thrombus on the echocardiogram $(n=1)$. Eighty three of the 126 patients (66\%) were taking $\beta$ blockers at the time of testing. The test was negative for ischaemia in 73 of 130 (56\%) patients and positive in $53(41 \%)$ patients (table 2).

\section{Drugs prescribed at discharge}

Drugs prescribed at discharge in the whole study population (262 patients) were as follows: aspirin 241 (92\%), $\beta$ blockers $183(70 \%)$, nitro-derivatives $182(70 \%)$, angiotensin converting enzyme inhibitors 147 (56\%), calcium antagonists 9 (3\%), and diuretics $10(4 \%)$.

\section{Clinical outcome}

At one year's follow up there were 26 events (one death, five non-fatal reinfarctions, 20 unstable angina requiring hospitalisation) in the early stress echocardiography group and 18 events (two reinfarctions, 16 unstable angina requiring hospitalisation) in the exercise ECG group (not significant). Table 3 shows clinical outcome according to test result. Table 4 shows the prognostic value of stress echocardiography and exercise ECG.

\section{Use of resources and cost analysis}

Number and timing of revascularisation procedures were similar for the two strategies (table 5) after adjusting for patients' characteristics. During the one year follow up, the total duration of hospitalisation, including index AMI and subsequent events, was a median of nine days (first quartile 8 , third quartile 14) for patients randomly assigned to stress echocardiography compared with 10 days (first quartile 8 ,

Table 6 Psychosocial assessment of the study groups

\begin{tabular}{|c|c|c|c|c|c|c|}
\hline & $\mathrm{n}$ & Group $1(n=132)$ & $\mathrm{n}$ & Group $2(n=130)$ & n & Combined $(n=262)$ \\
\hline \multicolumn{7}{|l|}{ Physical } \\
\hline At 1 month & 89 & $2.67(2.22,3.44)$ & 96 & $2.56(2.00,3.22)$ & 185 & $2.56(2.00,3.33)$ \\
\hline At 6 months & 80 & $2.33(1.78,3.22)$ & 89 & $2.44(1.78,2.89)$ & 169 & $2.33(1.78,3.00)$ \\
\hline At 1 year & 42 & $2.94(2.44,3.67)$ & 52 & $2.67(2.33,3.11)$ & 94 & $2.78(2.33,3.56)$ \\
\hline \multicolumn{7}{|l|}{ Emotional } \\
\hline At 1 month & 92 & $3.20(2.67,3.70)$ & 98 & $2.87(2.47,3.27)$ & 190 & $3.00(2.53,3.53)$ \\
\hline At 6 months & 85 & $3.07(2.53,3.60)$ & 85 & $2.93(2.53,3.20)$ & 170 & $3.00(2.53,3.40)$ \\
\hline At 1 year & 42 & $3.37(3.07,3.73)$ & 50 & $3.20(2.80,3.40)$ & 92 & $3.20(2.90,3.73)$ \\
\hline \multicolumn{7}{|l|}{ Social } \\
\hline At 1 month & 94 & $3.00(2.57,3.43)$ & 100 & $2.86(2.43,3.29)$ & 194 & $2.86(2.57,3.43)$ \\
\hline At 6 months & 85 & $2.86(2.43,3.43)$ & 86 & $2.86(2.29,3.14)$ & 171 & $2.86(2.29,3.29)$ \\
\hline At 1 year & 42 & $3.2(2.86,3.43)$ & 51 & $3.00(2.86,3.43)$ & 93 & $3.14(2.86,3.43)$ \\
\hline
\end{tabular}


third quartile 14) for patients randomly assigned to exercise ECG. Costs were similar for the two strategies (table 5).

\section{Psychosocial assessment}

No significant differences were found in any psychosocial measures between the two strategies (table 6).

\section{DISCUSSION}

We recently reported that a systematic early search for ischaemia with stress echocardiography followed by early discharge in case of a negative test result gives a similar clinical outcome to clinical evaluation and post-discharge exercise ECG in patients with uncomplicated AMI and normal residual left ventricular function. ${ }^{13}$ This was associated with a reduction of costs. Nevertheless, the COSTAMI trial did not compare stress echocardiography with predischarge exercise ECG in this patient population. The COSTAMI-II trial shows that early stress echocardiography allows risk stratification after AMI as effectively as predischarge exercise ECG with similar costs during follow up.

The link between instrumental signs of residual ischaemia and determination of prognosis is difficult to prove. The DANAMI (Danish trial in acute myocardial infarction) study ${ }^{14}$ showed that invasive treatment of patients after an AMI with inducible ischaemia results in a reduced incidence of reinfarction, fewer admissions for unstable angina, and a lower prevalence of stable angina but not in a reduction in mortality. This is explained in part by the low prevalence of future events and consequently the loss of the predictive capacity of non-invasive testing in the thrombolytic era, ${ }^{15}$ as well as the unpredictability of destabilisation of an atherosclerotic plaque that is very often less than critical. Nevertheless, the so called "soft end points" such as anginal episodes requiring hospitalisation are of growing interest in the present era of managed care and it seems important to identify the most cost effective strategy after the acute phase. In spite of the proliferation of prognostic studies using various methods with the aim of identifying patients at higher risk after hospital discharge, head to head randomised studies comparing various stratification modalities are lacking.

Exercise ECG is still the most commonly used non-invasive method for risk stratification before hospital discharge. It has an unsatisfactory positive predictive value and the correlation of positive test and mortality has been substantially refuted. ${ }^{16}$ Nevertheless, the negative predictive value is good even for patients treated thrombolytically. ${ }^{17}{ }^{18}$ Consistently with the aforementioned trials, in our study, patients with negative test results had excellent survival rates.

Nevertheless, soft events were not unusual in the follow up of patients with a negative exercise ECG. A possible explanation for this finding is that our patients exercised under full treatment, and two thirds of the patients were taking $\beta$ blockers at the time of exercise, which may have reduced test sensitivity in showing residual ischaemia. The relative prognostic value of stress echocardiography and exercise ECG has been studied ${ }^{3}$ but, to the best of our knowledge, this is the only randomised trial with the prespecified aim of comparing cost effectiveness head to head in the two risk stratification modalities used before hospital discharge. A high negative predictive value of both methods with low positive predictive value was confirmed in our study and no significant differences were observed in events or costs at one year of follow up. This is consistent with the hypothesis that stress echocardiography can be safely used as a valid alternative to exercise ECG. Previous studies have shown that pharmacological stress echocardiography risk stratifies patients recovering from an uncomplicated AMI and provides incremental information on top of clinical and exercise ECG data. ${ }^{5}$ Nevertheless, the main advantage of echocardiography over exercise is its safety in the early days after the acute event, when an exercise induced increase of double product should be avoided. ${ }^{19}$

Some limitations of the study must be acknowledged. Firstly, the trial is a multicentre, international experience and therefore costs in medical care may differ substantially between institutions in different countries. Secondly, a shorter duration of hospital stay by protocol may have reduced costs in the stress echocardiography group. Thirdly, exercise ECG was recorded while the patient was taking medication, which may have reduced the accuracy of the exercise test in detecting ischaemia. Nevertheless, this approach is current clinical practice and is a reference standard. Also, concomitant anti-ischaemic treatment at the time of testing heavily modulates the prognostic value of pharmacological stress echocardiography. Fourthly, stress echocardiograms were not interpreted off site, to ensure that performance of the test could be evaluated according to real world standards. However, the enrolling centres passed a quality control to guarantee a homogeneous interpretation in stress echocardiogram reading. Nevertheless, reading the stress echocardiograms on site may have influenced the interobserver variability in a negative way.

In conclusion, this study shows that conventional predischarge risk stratification with exercise ECG and early stress echocardiographic examination allow similar cost effective hospital discharge of patients after an uncomplicated AMI.

\section{ACKNOWLEDGEMENTS}

This study is a finalised project of the Veneto Region, Research project $n^{\circ} 825 / 06 / 98$, endorsed by the Working Groups of Cardiac Rehabilitation and Exercise Physiology and Echocardiography of the European Society of Cardiology and by the Italian Society of Cardiology. We acknowledge the support of the Cardiovascular Research Foundation, S Giacomo Hospital, and "Club Amici del Cuore-ONLUS", Castelfranco Veneto, Italy and of the IRCAB Foundation, Udine, Italy (Core Laboratory).

\section{Authors' affiliations}

A Desideri, L Celegon, R Bigi, Cardiovascular Research Foundation, $S$ Giacomo Hospital, Castelfranco Veneto, Italy

P M Fioretti, D Gregori, IRCAB Foundation, S Maria della Misericordia Hospital, Udine, Italy

L Cortigiani, Cardiology Department, Campo di Marte Hospital, Lucca, Italy

G Trocino, Cardiology Department, S Gerardo Hospital, Monza, Italy C Astarita, Cardiology Department, Sorrento General Hospital, Sorrento, Italy

J Bax, University Medical Centre, Leiden, the Netherlands

J Velasco, Cardiology Department, University General Hospital, Valencia, Spain

S Pirelli, Cardiology Department, General Hospital, Cremona, Italy E Picano, CNR Institute of Clinical Physiology, Pisa, Italy

\section{APPENDIX}

\section{COSTAMI STUDY GROUP}

\section{Steering committee}

Alessandro Desideri, Cardiovascular Research Foundation, Castelfranco Veneto, Italy (Chairperson); Paolo Fioretti, IRCAB Foundation, Udine, Italy; Salvatore Pirelli, General Hospital, Cremona, Italy; Leopoldo Celegon, Cardiovascular Research Foundation, Castelfranco Veneto, Italy; Clara Carpeggiani and Eugenio Picano, CNR Institute of Clinical Physiology Pisa, Italy; Jean Louis Vanoverschelde, University of Luvain, Brussels, Belgium; and Miodrag Ostojic, University Institute for Cardiovascular diseases, Belgrade, Yugoslavia. 


\section{Database and statistical analysis}

Dario Gregori, Gaetano Nucifora, Marco Ghidina, Elena Gremese, and Massimo Trentin, IRCAB Foundation, Udine, Italy; Riccardo Bigi, Cardiovascular Research Foundation, Castelfranco Veneto, Italy; and Jeroen Bax, University Medical Centre, Leiden, the Netherlands.

\section{Psychological and quality of life assessments}

Patricia Rozbowsky, IRCAB Foundation, Udine, Italy.

\section{Quality control in echocardiography}

Eugenio Picano, CNR Institute of Clinical Physiology, Pisa, Italy

\section{Investigators}

Giuseppe Trocino and Manuela Cereda, S Gerardo Hospital, Monza, Italy; Costantino Astarita, Sorrento General Hospital, Sorrento, Italy; Lauro Cortigiani, Campo di Marte Hospital, Lucca, Italy; Patrizia Maras, Trieste Maggiore Hospital, Trieste, Italy; Marek Demczuk, Primate Cardinal Stefan Wyszynski Hospital, Sieradz, Poland; Jose Velasco, University General Hospital, Valencia, Spain.

\section{REFERENCES}

1 Van de Werf F, Ardissino D, Betriu A, et al. Management of acute myocardial infarction in patients presenting with ST-segment elevation. The task force on the management of acute myocardial infarction of the European Society of Cardiology. Eur Heart J 2003;24:28-66.

2 Picano E, Landi $\mathrm{P}$, Bolognese $\mathrm{L}$, et al. Prognostic value of dipyridamole echocardiography early after uncomplicated myocardial infarction: a large scale, multicenter trial. Am J Med 1993;6:608-18

3 Sicari R, Landi P, Picano E, et al, on behalf of the EPIC (Echo Persantine International Cooperative) and EDIC (Echo Dobutamine International Cooperative) Study Groups. Exercise-electrocardiography and/or pharmacological stress echocardiography for noninvasive risk stratification early after uncomplicated myocardial infarction: a prospective international large scale multicenter study. Eur Heart J 2002;23:1030-7.

4 Desideri A, Bigi R, Suzzi G, et al. Stress echocardiography and exercise electrocardiography for risk stratification after non-Q-wave uncomplicated myocardial infarction. Am J Cardiol 1999;84:739-41.
5 Bigi R, Galati A, Desideri A, et al. Incremental prognostic value of stress echocardiography as adjunctive test to exercise electrocardiography following uncomplicated myocardial infarction. Heart 2001;85:417-23.

6 Schiller N, Shah P, Crawford M, et al. Recommendations for quantitation of the left ventricle by two-dimensional echocardiography. American Society of Echocardiography committee on standards, subcommittee on quantitation of two-dimensional echocardiograms. J Am Soc Echocardiogr 1989;2:358-67.

7 Arnese M, Fioretti PM, Cornel J, et al. Akinesis becoming dyskinesis during high-dose dobutamine stress echocardiography: a marker of myocardial ischemia or a mechanical phenomenon? Am J Cardiol 1994;73:896-9.

$8 \mathrm{Lim} \mathrm{L,} \mathrm{Valenti} \mathrm{L,} \mathrm{Knapp} \mathrm{J,} \mathrm{et} \mathrm{al.} \mathrm{A} \mathrm{self} \mathrm{administered} \mathrm{quality} \mathrm{of} \mathrm{life} \mathrm{questionnaire}$ after acute myocardial infarction. J Clin Epidemiol 1993;46:1249-56.

9 Locallio AR, Berlin JA, Ten Have TR, et al. Adjustments for center in multicenter studies: an overview. Ann Intern Med 2001;135:112-23.

10 Lindstrom MJ, Bates DM. Nonlinear mixed effects models for repeated measures data. Biometrics 1990;46:673-87.

11 Wei L, Lin D, Weissfeld L. Regression analysis of multivariate incomplete failure time data by modeling marginal distributions. J Am Stat Assoc 1989;84:1065-73.

12 Liang K, Zeger SL. Longitudinal data analysis using generalized linear models. Biometrika 1986;73:13-22.

13 Desideri A, Fioretti PM, Cortigiani L, et al. Cost of strategies after myocardial infarction (COSTAMI): a multicenter, international, randomized trial for costeffective discharge affer uncomplicated myocardial infarction. Eur Heart $J$ 2003:24:1630-9.

14 Madsen JK, Grande P, Saunamaki K, et al. Danish multicenter randomized study of invasive versus conservative treatment in patients with inducible ischemia after thrombolysis in acute myocardial infarction (DANAMI). Danish trial in acute myocardial infarction. Circulation 1997;96:748-55.

15 Marx B, Feinstein A. Methodologic sources of inconsistent prognosis for postacute myocardial infarction. Am J Med 1995;98:537.

16 Stevenson R, Umachandron V, Ranjadaylon K, et al. Reassessment of treadmill stress testing for risk stratification in patients with myocardial infarction treated by thrombolysis. Br Heart J 1993;70:415-20.

17 Piccalo' G, Pirelli S, Massa D, et al. Value of negative predischarge exercise testing in identifying patients at low risk after acute myocardial infarction treated by systemic thrombolysis. Am J Cardiol 1992;70:31-3.

18 Volpi A, De Vita C, Franzosi MG, et al. Determinants of 6-month mortality in survivors of myocardial infarction after thrombolysis. Results of the GISSI-2 data base. The ad hoc working group of the Gruppo Italiano per lo Studio della Sopravvivenza nell'Infarto (GISSI)-2 Data Base. Circulation 1993;88:416-29.

19 Chiarella F, Domenicucci S, Bellotti P, et al. Dipyridamole echocardiographic test performed 3 days after an acute myocardial infarction: feasibility, tolerability, safety and in-hospital prognostic value Eur Heart $J$ 1994; 15:842-50

\section{Committee on Publication Ethics Seminar 2005 Friday 11 March 2005, 9.30 am - 5 pm, BMA House, London}

This year's seminar will focus on COPE's new Code of Conduct for Editors and interactive workshops on common ethical and editorial dilemmas. The seminar is for editors, authors, and all those interested in increasing the standard of publication ethics.

The Code aims to set a new basic standard for the ethical conduct of editors and sets out guidelines for quality and correcting the record, standing by decisions made, ethics committee approval, consent for publication confidentiality of submitted material, guidance to authors, pursuing misconduct, relationship to publishers, owners, and advertisers, and conflict of interest. The code also creates a mechanism to refer a complaint to COPE if an editor has breached the code.

The seminar will include:

- The new Code of Conduct for Editors

- Dr lona Heath, Chair BMJ Ethics Committee-research, audit, and ethics committee approval

- COPE's new website-full text and keyword searching for COPE's advice on specific issues, for example research misconduct, conflict of interest, and deception

- Interactive workshops-common ethical and editorial dilemmas for editors

- Opportunities to network with other editors and share your experiences and challenges

The seminar is free for COPE members and $£ 30.00$ for non-members. Numbers are limited and early booking is advisable. For registrations or more information please contact Sam Knottenbelt at cope@bmigroup.com or call 0207383 6602. For more information on COPE see www.publicationethics.org.uk/ 